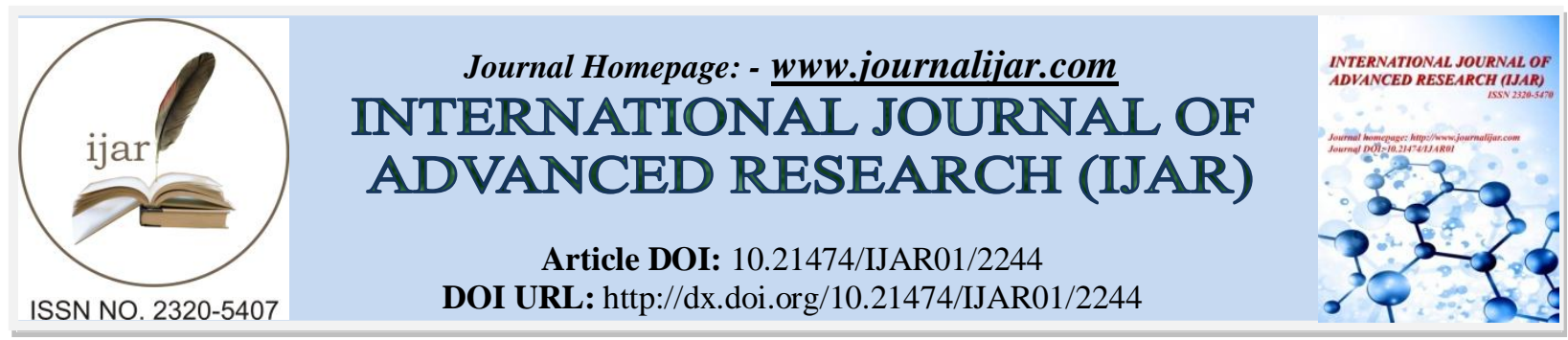

RESEARCH ARTICLE

\title{
ENHANCING MEDIA COMPOSITIONS FOR NATTOKINASE PRODUCTION: AN APPROACH OF RESPONSE SURFACE METHODOLOGY
}

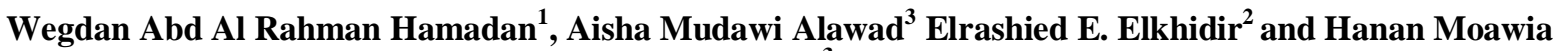 Ibrahim $^{3}$.}

1. Ahfad University for Women.

2. Faculty of Agriculture, University of Khartoum.

3. Central Lab Ministry of Higher Education and Scientific Research.

\section{Manuscript Info}

(.........................

Manuscript History

Received: 29 September 2016

Final Accepted: 30 October 2016

Published: November 2016

Key words:-

Nattokinase, Fibrinolytic Enzyme,

Bacillus subtilis, Optimization,

Response Surface Methodology

\section{Abstract}

This study aimed to isolate and characterize a potent Bacillus strain to produce a fibrinolytic enzyme, nattokinase, with highest activity under optimal media compositions. The study was carried out on 30 samples collected from different regions in Sudan. Primary screening of the microorganism showed that sixteen out of thirty samples (53\%) showed a clear large inhibition zone in casein hydrolysis and blood heamolysis methods. Ten out of sixteen $(63 \%)$ of the selected sample considered as Bacillus subtilis according to morphological, microscopic and biochemical analysis. Selective medium was prepared for the extraction and production of nattokinase from these new isolates. Response Surface Methodology (RSM) was employed to optimize a fermentation medium for the production of nattokinase by Bacillus subtilis at $\mathrm{pH} 7.2$, temperature of $37^{\circ} \mathrm{C}$ and agitation rate of $140 \mathrm{rpm}$. The four variables involve in this study were glucose, maltose, peptone and yeast extract and consistent $\mathrm{MgSo}_{4}$ and $\mathrm{K}_{2} \mathrm{HPO}_{4}$. The result showed that the peptone had no a significant effect on nattokinase production the optimized medium containing (\%) glucose 1.45, maltose 5.5, yeast extract 2.75 and no level of peptone incorporated to the medium. The predicted response of nattokinase activity will be of 0.827917 Fibrinolytic Unit (FU).

Copy Right, IJAR, 2016,. All rights reserved.

\section{Introduction:-}

Nattokinase is an enzyme extracted and purified from a Japanese food called natto. natto, a fermented cheese- like food that has been used in Japan for over 1000 year.(Haritha and Meena, 2011). Nattokinase is produced by Bacillus subtilis natto (a naturally-occurring proteolytic enzyme) supports normal, healthy blood flow and circulation. This may contribute to the regular healthy function of the heart and cardiovascular system by maintaining proper blood flow, thinning the blood and preventing blood clots, also can hydrolyze fibrin in the blood clots both directly(act as fibrinogen) and indirectly. Indirectly, it activates pro-urokinase and tissue plasminogen activator $\{\mathrm{t}-\mathrm{PA}\}$, supporting the fibrinolytic activity of plasmin (Borah et al., 2012). The fibrinolytic activity of Nattokinase is four times higher than plasmin (Sumi et al 1990). Nattokinase is an enzyme considered to be promising remedy for thrombosis healing due to its potent fibrinolytic activity. Due to its presence in food and relatively robust fibrinolytic activity, nattokinase has benefits over other available commercially used drugs in prophylactic and extended effects, 
particularly due to stability in gastrointestinal tract and comfortable oral administration. Oral administration of nattokinase could diminish plasma levels of fibrinogen, factor VIII, and factor VII which may be useful as a nutraceutical for cardiovascular disease (Ibrahim et al., 2015).. Nattokinase is serine protease with 275 amino acid residues and a molecular weight of 27,728 Dalton. Fibrinolytic enzymes such as urokinase, streptokinase and nattokinase are too costly and also used through intravenous instillation, needs large scale production by some alternative methods and high purity. So extraction of nattokinase from bacterial sources are very effective and useful (Borah et al., 2012). On the basis of its food origin, nattokinase has relatively strong fibrinolytic activity, stable in the gastrointestinal tract, and convenient for oral administration, subtilisin nattokinase has advantages for commercially used medicine for preventative and prolonged effect (Uversky et al., 2004) .The list of conditions likely to be ameliorated with use of nattokinase includes: Atherosclerosis, Coronary artery disease, Hypertension, Peripheral vascular disease- arterial atherosclerosis, venous thrombi, strokes and thrombus formation -including venous clot, arterial-wall thrombi with atherosclerosis, atrial- chamber thrombi (occurs in chronic a trial fibrillation), hemorrhoids, eye thrombosis and senile ementia associated with cerebral thrombi formation (Martin et al., 2002). No significant nattokinase side effects have yet been reported in medical literature when used without other anticoagulants, However; this does not mean that nattokinase is side effect free. It just means that we don't have enough human trials to know all the benefit and risk with nattokinase treatment .Using nattokinase with warfarin or aspirin could enhance bleeding rise (Martin et al., 2002).

A novel fermentation medium is of critical importance because medium composition can significantly affect product yield. Media component play a very important role in enhancing cell growth and increase the target product accumulation, therefore, optimization of medium composition study is very important. One of the commonest operations in the study of microorganism is the development of appropriate conditions (Media compositions and physical environment) to achieve maximum cell and metabolic product yield or enhancement of enzyme production. Optimization is one of the commonest operations in the study of microorganism for the development of media compositions to achieve maximum metabolic product yield. It can be carried out in several ways changing one variable at a time (classical method). This approach is however, extremely inefficient in locating the true optimum when interaction effect are present. To overcome the problems with interaction effects, variable efficient medium will be achieved when mathematical optimization techniques in-terms of Response Surface Methodology (RSM) were applied. RSM is a statistical technique for the modeling and optimization of multiple variables, which determines the optimum process conditions through combining experimental designs with interpolation by first- or second-order polynomial equations in a sequential testing procedure (Myers et al., 2009). The microorganism when cultured in an appropriate, suitable and selective medium using RSM will enhance the concentration of target product. (Ibrahim and Elkhidir, 2011). This study aimed to the optimization of media compositions to enhance nattokinase production using statistical experimental design.

\section{Materials and Method:-}

Sampling:-

30 soil samples were collected into sterilized plastic bags from potatoes farms from different locations in Sudan. Samples were taken from $15-20 \mathrm{~cm}$ depth after removing approximately $3 \mathrm{~cm}$ of earth surface. Study was conducted from October 2015 to February 2016.

Isolation of microorganism was performed by pour plate technique (You and Park 2004).

\section{Primary screening of nattokinase:-}

\section{Casein hydrolysis method:-}

Casein hydrolysis medium was prepared from two solution : solution A prepared by dissolving $10 \mathrm{~g}$ of skim milk powder in $100 \mathrm{ml}$ distilled water and solution B was prepared by dissolving $2 \mathrm{~g}$ agar in $100 \mathrm{ml}$ distilled water. Solution A and B were autoclaved allowed to cool to $50^{\circ} \mathrm{C}$ and combined before they poured into sterile Petridishes. The inoculated plates were incubated at $37^{\circ} \mathrm{C}$ for $18 \mathrm{hrs}$. Appearance of a clear zone around each colony indices a positive result (Willim and Cross, 1971).

\section{Blood hemolysis method:-}

Blood hemolysis medium prepared by adding $10 \mathrm{ml}$ of filter-sterilized blood to $100 \mathrm{ml}$ of sterilized nutrient agar in $250 \mathrm{ml}$-conical flasks and the contents were mixed gently to avoid any bubble formation. Clean uncontaminated plates were inoculated each with one test organism isolates, and incubated for $24 \mathrm{hrs}$ at $37^{\circ} \mathrm{C}$. Hemolysis was 
indicated by the presence of clear zones around the colonies (Collins and Lynee, 1995). The selected isolate that showed a clear inhibition zone were identified and characterized based on it's microscopically, biochemical characteristics according to Collins and Lynee 1995.

\section{Enzyme extraction:-}

The identified microorganism B. subtilis was grown on basal medium containing $(\mathrm{g} / \mathrm{L})$ soya peptone $10, \mathrm{~K}_{2} \mathrm{HPO}_{4}$, 2.0, $\mathrm{Mg} \mathrm{So}_{4}$ 1.0, Maltose 20, Yeast extract 10, Glucose 2.0 and completed to 1000 with distilled water. The $\mathrm{pH}$ was adjusted to 7.2 with $2 \mathrm{M}$ acetic acid and $2 \mathrm{M} \mathrm{NaOH}$. Medium was sterilized by autoclaving at $121^{\circ} \mathrm{C}$ for $15 \mathrm{~min}$. and cooled at room temperature. $1 \mathrm{ml}$ of uniformly prepared suspension of $B$. subtilis was used as inoculums, incubated at $37^{\circ} \mathrm{C}$ and agitated at $150 \mathrm{rpm}$ in orbital shaker incubator. After 2 days of fermentation, cells were harvested by centrifugation (Dubey et al., 2011).

\section{Enzyme activity assays:-}

Blood clot dissolving assay:-

Sterile empty micro-centrifuge tubes were taken labeled suitably and weighted (W1). $500 \mu 1$ of freshly collected blood were transferred into each micro-centrifuge tube and incubated at $37^{\circ} \mathrm{C}$ for $45 \mathrm{~min}$. After clot formation, serum was completely removed by aspiration without disturbing the clot. The micro-centrifuge with the clot was weighted (W2). A $500 \mu 1$ of supernatants were added to the tubes and $500 \mu 1$ of distilled water in control tube. All tubes were incubated at $37^{\circ} \mathrm{C}$ for $24 \mathrm{hrs}$. Then the fluid on each tube was removed and tubes were weighted (W3). The percentage of clot lysis was calculated using the following equation (Parsad et al., 2006).

$\begin{array}{ll}\text { Percentage lysis }=\frac{100-(\mathrm{W} 3-\mathrm{W} 1)}{(\mathrm{W} 2-\mathrm{W} 1)} \times 100 & \text { Equ. (1) }\end{array}$

\section{Assay of Fibrinolytic Activity:-}

Fibrinolytic activity was measured by hydrolysis of fibrin [Wu 2005]. Boric acid buffer $(1.4 \mathrm{~mL}, 50 \mathrm{mmol} / \mathrm{L}, \mathrm{pH}$ 8.5 ) and $0.4 \mathrm{~mL}$ of $0.72 \%(\mathrm{w} / \mathrm{v})$ fibrinogen solution were mixed in a glass tube and incubated at $37^{\circ} \mathrm{C}$ for $5 \mathrm{~min}$. The mixture was then added with $0.1 \mathrm{~mL}$ of thrombin $(10 \mathrm{U} / \mathrm{mL})$ in boric acid buffer $(50 \mathrm{mmol} / \mathrm{L}, \mathrm{pH} 8.5)$ and further incubated at $37^{\circ} \mathrm{C}$ for additional $10 \mathrm{~min}$. Then $0.1 \mathrm{~mL}$ of diluted enzyme solution was added to the reaction mix and incubated at $37^{\circ} \mathrm{C}$ for $60 \mathrm{~min}$. The reaction was terminated by incubating $2 \mathrm{~mL}$ of $0.2 \mathrm{~mol} / \mathrm{L}$ trichloroacetic acid (TCA) for $20 \mathrm{~min}$ and centrifuged at $5000 \mathrm{r} / \mathrm{min}$ for $10 \mathrm{~min}$. Absorbance of the supernatant (Ar) and appropriate blanks (Ac) was measured at $275 \mathrm{~nm}$. One unit fibrinolytic enzyme activity was defined as the amount of enzyme required to produce an increment in $A$ equal to 0.001 in $60 \mathrm{~min}$. (Tillett and Garner 1933).

Fibrinolytic Unit $(\mathbf{F U})=\frac{(A r-A c) \times \text { diluted ratio of sample }}{(0.001 \times 60 \times 0.1)} \quad$ Equ.(2)

\section{Experimental design:-}

The optimization of medium compositions including nitrogen source; soya peptone and yeast extract, carbon source; maltose and glucose, at constant concentration of $\mathrm{K}_{2} \mathrm{HPO}_{4}(0.2 \%)$ and $\mathrm{Mg} \mathrm{So}_{4}(0.1 \%)$ and constant culture conditions: $\mathrm{pH}$ of 7.2, temp. of $37^{\circ} \mathrm{C}$ and $150 \mathrm{rpm}$. Minitab software version 16 was used for the optimization of reaction parameters, and each variable needed to be investigated at five levels $(-\alpha,-1,0,+1,+\alpha)$. From previous data on literature the chosen minimum and maximum concentrations of the variables are; glucose $1 \%-4 \%$, maltose $0.1 \%-1 \%$, peptone $0.5 \%-2 \%$ and yeast extract $0.5 \%-2 \%$, their values in actual and coded form was listed in (Table 1). The full experimental plan (Table2).

Table 1:- Process of four variables-two levels response surface design

\begin{tabular}{|c|c|c|c|c|}
\hline \multirow[t]{2}{*}{ Independent variables } & \multicolumn{2}{|c|}{ Symbol } & \multicolumn{2}{|c|}{ Levels } \\
\hline & Coded & Uncoded & Coded & Uncoded \\
\hline \multirow[t]{3}{*}{ Maltose } & $\mathbf{X}_{1}$ & $\%$ & -1 & 0.1 \\
\hline & & & $\mathbf{0}$ & 0.55 \\
\hline & & & +1 & 1 \\
\hline \multirow[t]{3}{*}{ Glucose } & $\mathbf{X}_{2}$ & $\%$ & -1 & 1 \\
\hline & & & $\mathbf{0}$ & 2.5 \\
\hline & & & +1 & 4 \\
\hline \multirow[t]{3}{*}{ Peptone } & $\mathbf{X}_{3}$ & $\%$ & -1 & 0.5 \\
\hline & & & $\mathbf{0}$ & 1.25 \\
\hline & & & +1 & 2 \\
\hline \multirow[t]{3}{*}{ Yeast extract } & $\mathbf{X}_{4}$ & $\%$ & -1 & 0.5 \\
\hline & & & $\mathbf{0}$ & 1.25 \\
\hline & & & +1 & 2 \\
\hline
\end{tabular}


The surface response for enzyme production as a function of selected key variables was determined. A two level full fractional factorial design with four variables consisting of two blocks and with 30 runs (24 combinations with 6 replication of the center point) were used Table (3).

\section{Result and Discussion:-}

Thirty presumptive soil samples collected from different locations were given number. Primary screening of the microorganism revealed that sixteen out of thirty (53\%) showed a clear large inhibition zone in casein hydrolysis and blood heamolysis methods this mean positive reaction, Plate (1) and Plate (2). Ten out of sixteen (63\%) of the selected sample consider as Bacillus subtilis according to morphological, microscopic and biochemical characteristic. These organisms showed gram positive, endo-spore forming, rods produce colonies which are dry, flat, and irregular, with lobate margin, also showed positive reactions in citrate test, Voges -prokauer experiment (V-P test), $6.5 \% \mathrm{NaCl}$ growth and starch hydrolysis test, and no growth at $55^{\circ} \mathrm{C}$. Ibrahim et al., 2015 found that six out of 25 samples (24\%) were shown to be Bacillus licheniformis for natokinase production where study of Isam Eldeen et al., he results were consistent with those reported by Peng et al., 2003 who had discovered a high fibrinolytic enzyme-producing strain Bacillus amyloliquefaciens DC-4 in Douchi. Our results findings showed 3 fold higher percentages of $63 \%$ is considered as Bacillus Subtilis natokinase producer from soil samples

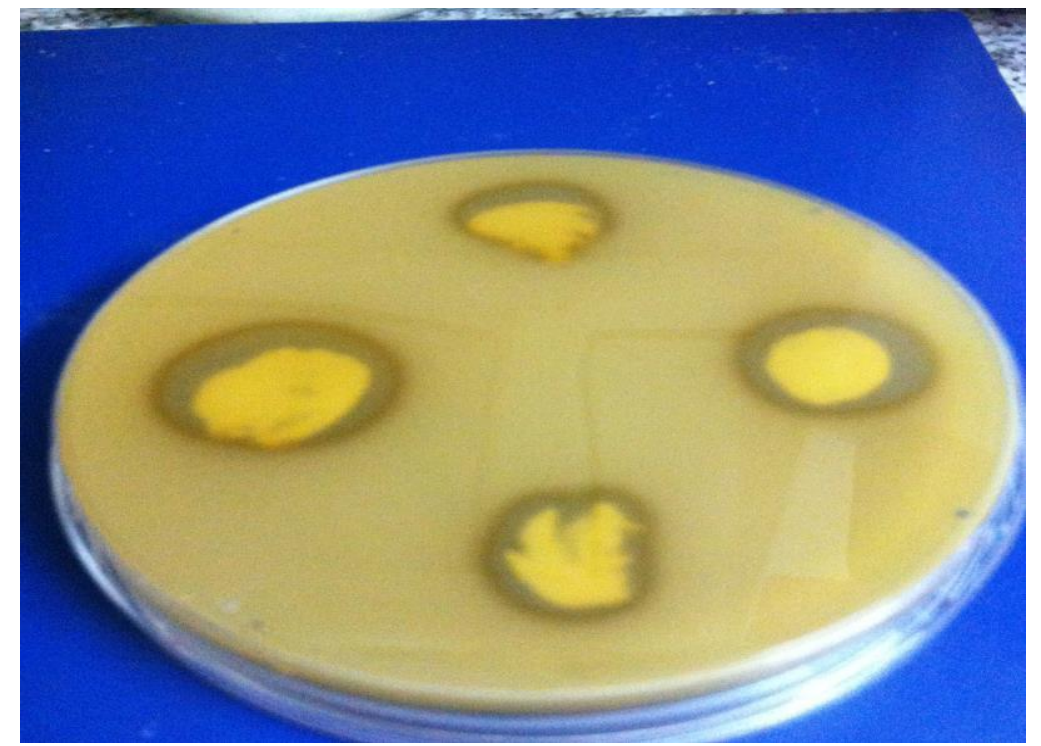

Plate 1:- Primary screening of the samples using Casein hydrolysis method 


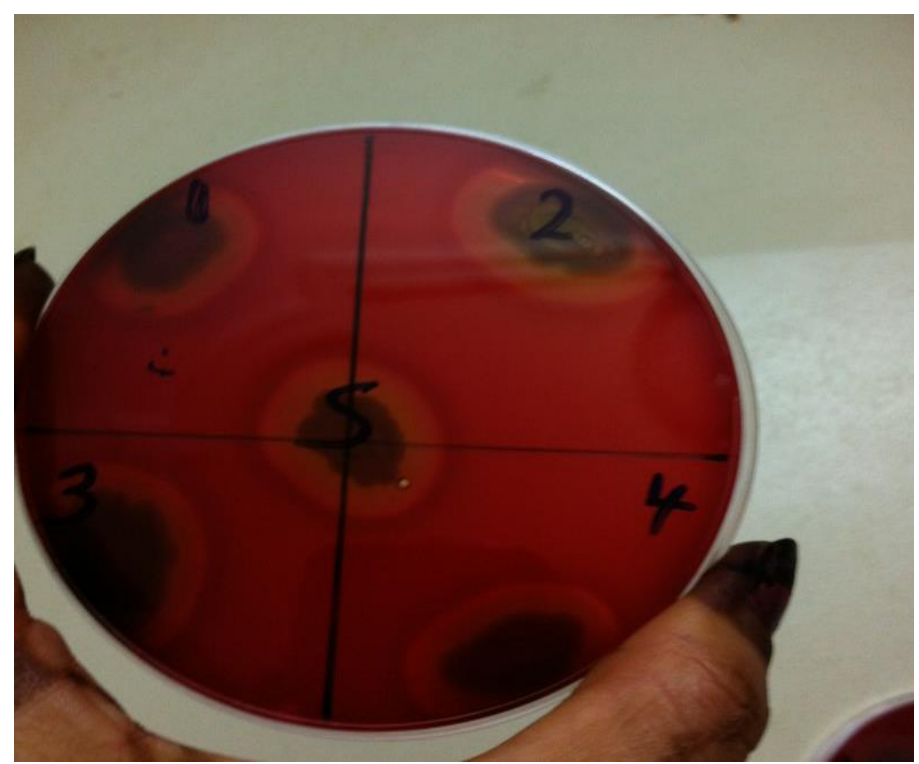

Plate 2:- Primary screening of the samples using blood heamolysis method

Nowadays, fibrinolytic enzyme produced by food microbe has become a research hotspot for its various advantages including: low cost, high activity, safe and non-toxic. Besides nattokinase, researchers also found that other fibrinolytic enzymes from microbe were employed for food fermentation, such as subtilisin DJ-4 of Bacillus sp. DJ4 from Korean food Doen-Jang. (Kim and Choi 2000). Nattokinase is traditionally produced by fermentation of various microorganisms, among which the genus Bacillus Subtilis natto is the preeminent nattokinase producer (Kim and Choi. 2000). Nattokinase can now be produced in batch culture, rather than relying on extraction from Nattō [Kwan et al., 2011]. In another study of Sumi et al., (1990) reported that when nattokinase was given to human subject by oral administration fibrinolytic activity and the amount of tPA and fibrin degradation product in plasma increased about two folds.

Table (2) below show the percentage of clot lysis obtained from eight selected and promising samples by calculating the clot lysis percentage from the below equation:

Percentage lysis $=\frac{100-(\mathrm{W} 3-\mathrm{W} 1)}{(\mathrm{W} 2-\mathrm{W} 1)} \mathrm{X100} \quad$ equ. (1)

Table 2:- Blood clot dissolving pattern of bacterial isolates

\begin{tabular}{|l|l|}
\hline Nattokinase producers & Percentage of clot lysis \% \\
\hline Stander Bacillus subltilis & $\mathbf{3 8 . 8 \%}$ \\
\hline Sample (1) & $\mathbf{3 8 . 2 8 \%}$ \\
\hline Sample(2) & $\mathbf{4 6 . 1 3 \%}$ \\
\hline Sample(3) & $\mathbf{4 8 . 1 \%}$ \\
\hline Sample(4) & $\mathbf{4 7 \%}$ \\
\hline Sample(10) & $\mathbf{7 5 \%}$ \\
\hline Sample(12) & $\mathbf{7 5 . 2 3 \%}$ \\
\hline Sample(13) & $\mathbf{7 5 . 0 3 \%}$ \\
\hline Sample (15) & $\mathbf{1 5 . 0 8 \%}$ \\
\hline
\end{tabular}

Maximum clot lysis was observed with sample (10), (12) and (13) of 75\%. 75.23 and $75.03 \%$ respectively, which is double the clot lysis percentage of the standard Bacillus subltilis (38.8\%) while sample (2), (3) and (4) were $46.13 \%, 48.1 \%$ and $47 \%$ respectively were slightly higher than the standard one. Sample (1) revealed approximately same clot lysis percentage as the standard one. The minimum clot lysis percentage was observed with sample (15) of $15.08 \%$. Our findings revealed that $75 \%$ of the samples are much higher than the percentage of the clot lysis of the standard Bacillus subltilis. According to result obtained we choice sample (12) for further study of media optimization using experimental design. The designs and results are listed in Table (3) 
Experimental design: Statistical experimental design has not been widely used in the biological sciences even though it has been commonly employed in many other areas such as industrial, chemical, engineering, agricultural, medical, and food sciences. The primary reason for this is that most biological research has not been involved in many manufacturing processes. The fermentation optimization can effectively and rapidly increase fibrinolytic enzyme production. (ZHANG et al., 2013). However, since genetic engineering, biomaterials, and bioprocess technologies like biodegradation and bioremediation have emerged, more people are getting interested in experimental designs to improve their biological processes and productions by shortening time and increasing efficiencies (Kwang-Min and David, 2005). Central composite design (CCD) allowed calculation of maximum production based on a set of experiments in which all the factors were varied within chosen ranges This method had been successfully applied in the optimization of medium composition. The experimental design and the result were shown in Table (3).

Table 3:- Experimental design and result of nattokinase activity $(\mathrm{FU} / \mathrm{ml})$

\begin{tabular}{|r|r|r|r|r|r|r|r|l|}
\hline StdOrder & RunOrder & PtType & Blocks & Glucose & Maltose & Peptone & Yeast extract & $\begin{array}{l}\text { Activity } \\
\text { (FU/ml }\end{array}$ \\
\hline 3 & 1 & 1 & 1 & 1 & 1 & 0.5 & 0.5 & 0.01 \\
\hline 2 & 2 & 1 & 1 & 4 & 0.1 & 0.5 & 0.5 & 0.00 \\
\hline 1 & 3 & 1 & 1 & 1 & 0.1 & 0.5 & 0.5 & 0.03 \\
\hline 19 & 4 & 0 & 1 & 2.5 & 0.55 & 1.25 & 1.25 & 0.11 \\
\hline 14 & 5 & 1 & 1 & 4 & 0.1 & 2 & 2 & 0.02 \\
\hline 8 & 6 & 1 & 1 & 4 & 1 & 2 & 0.5 & 0.14 \\
\hline 6 & 7 & 1 & 1 & 4 & 0.1 & 2 & 0.5 & 0.11 \\
\hline 9 & 8 & 1 & 1 & 1 & 0.1 & 0.5 & 2 & 0.11 \\
\hline 5 & 9 & 1 & 1 & 1 & 0.1 & 2 & 0.5 & 0.37 \\
\hline 12 & 10 & 1 & 1 & 4 & 1 & 0.5 & 2 & 0.24 \\
\hline 15 & 11 & 1 & 1 & 1 & 1 & 2 & 2 & 0.24 \\
\hline 13 & 12 & 1 & 1 & 1 & 0.1 & 2 & 2 & 0.16 \\
\hline 18 & 13 & 0 & 1 & 2.5 & 0.55 & 1.25 & 1.25 & 0.28 \\
\hline 16 & 14 & 1 & 1 & 4 & 1 & 2 & 2 & 0.06 \\
\hline 4 & 15 & 1 & 1 & 4 & 1 & 0.5 & 0.5 & 0.07 \\
\hline 10 & 16 & 1 & 1 & 4 & 0.1 & 0.5 & 2 & 0.19 \\
\hline 7 & 17 & 1 & 1 & 1 & 1 & 2 & 0.5 & 0.12 \\
\hline 17 & 18 & 0 & 1 & 2.5 & 0.55 & 1.25 & 1.25 & 0.01 \\
\hline 20 & 19 & 0 & 1 & 2.5 & 0.55 & 1.25 & 1.25 & 0.16 \\
\hline 11 & 20 & 1 & 1 & 1 & 1 & 0.5 & 2 & 0.18 \\
\hline 26 & 21 & -1 & 2 & 2.5 & 0.55 & 2.75 & 1.25 & 0.13 \\
\hline 21 & 22 & -1 & 2 & -0.5 & 0.55 & 1.25 & 1.25 & 0.11 \\
\hline 25 & 23 & -1 & 2 & 2.5 & 0.55 & -0.25 & 1.25 & 0.08 \\
\hline 27 & 24 & -1 & 2 & 2.5 & 0.55 & 1.25 & -0.25 & 0.11 \\
\hline 24 & 25 & -1 & 2 & 2.5 & 1.45 & 1.25 & 1.25 & 0.09 \\
\hline 22 & 26 & -1 & 2 & 5.5 & 0.55 & 1.25 & 1.25 & 0.14 \\
\hline 30 & 27 & 0 & 2 & 2.5 & 0.55 & 1.25 & 1.25 & 0.15 \\
\hline 29 & 29 & 0 & 2 & 2.5 & 0.55 & 1.25 & 1.25 & 0.01 \\
\hline 28 & 30 & -1 & 2 & 2.5 & 0.55 & 1.25 & 2.75 & 0.37 \\
\hline & & & & & & & & \\
\hline & & & & & & & \\
\hline
\end{tabular}

The regression coefficient, p-values and determination coefficient $\left(\mathrm{R}^{2}\right)$ for full quadratic model for nattokinase production are presented in Table (4). This model was tested for adequacy by the analysis of variance implied that the model is significant with high satisfactory value of $\mathrm{R}^{2}$ of $79.40 \%$ which indicates that only $20.60 \%$ of total variation is not explained by the model. This indicated that the variation in those selected factors could explain the variation in nattokinase activity up to $79.40 \%$. These made the fitted second-order polynomial more acceptable. The estimated equation of the model for nattokinase activity showed significant positive linear effect for peptone and yeast extract, these variables will significantly increase nattokinase activity, while glucose and maltose showed positive effect, but not significant. The interaction between glucose and peptone showed highly significant positive effect, which indicates that interactions of both factors required for nattokinase activity Table (4). 
Table 4:- Estimated Regression Coefficients for Response

\begin{tabular}{|c|c|c|}
\hline Term & Coefficients & P value \\
\hline Constant & $\mathbf{- 0 . 1 5 6 6 1 5}$ & $\mathbf{0 . 0 2 8}$ \\
\hline Glucose & $\mathbf{0 . 0 3 2 3 3 5}$ & $\mathbf{0 . 6 4 9}$ \\
\hline Maltose & $\mathbf{0 . 0 3 0 5 6 2}$ & $\mathbf{0 . 3 7 4}$ \\
\hline Peptone & $\mathbf{0 . 1 8 5 1 6 7}$ & $\mathbf{0 . 0 0 1}$ \\
\hline Yeast & $\mathbf{0 . 1 0 2 6 4 8}$ & $\mathbf{0 . 0 3 6}$ \\
\hline Glucose*Glucose & $\mathbf{0 . 0 0 0 3 8 0}$ & $\mathbf{0 . 9 0 1}$ \\
\hline Maltose*Maltose & $\mathbf{0 . 0 1 6 5 6 4}$ & $\mathbf{0 . 6 2 7}$ \\
\hline Peptone*Peptone & $\mathbf{0 . 0 1 0 4 0 7}$ & $\mathbf{0 . 4 0 1}$ \\
\hline Yeast*Yeast & $\mathbf{0 . 0 1 1 5 9 3}$ & $\mathbf{0 . 3 5 1}$ \\
\hline Glucose*Maltose & $\mathbf{0 . 0 0 0 5 5 6}$ & $\mathbf{0 . 9 6 7}$ \\
\hline Glucose*Peptone & $\mathbf{0 . 0 3 0 8 8 9}$ & $\mathbf{0 . 0 0 1}$ \\
\hline Glucose*Yeast & $\mathbf{0 . 0 1 5 8 8 9}$ & $\mathbf{0 . 0 6 2}$ \\
\hline Maltose*Peptone & $\mathbf{0 . 0 0 8 5 1 9}$ & $\mathbf{0 . 7 5 0}$ \\
\hline Maltose*Yeast & $\mathbf{0 . 0 4 3 7 0 4}$ & $\mathbf{0 . 1 1 7}$ \\
\hline Peptone*Yeast & $\mathbf{- 0 . 0 6 1 5 5 6}$ & $\mathbf{0 . 0 0 1}$ \\
\hline
\end{tabular}

$\mathrm{R}^{2}=79.40 \%$

According to the results of RSM, we were able to calculate the coefficients of the model equation and predict the maximal value of enzyme production. The general model of polynomial equation for the four variables and response values were given as follows:

Nattokinase production $=-0.126+0.07 \mathrm{X}_{1}+0.03 \mathrm{X}_{2}+0.195 \mathrm{X}_{3}+0.000 .103 \mathrm{X}_{4}+0.017 \mathrm{X}_{22}+0.013 \mathrm{X}_{33}-0.011 \mathrm{X}_{44}+$ $0.001 \mathrm{X}_{1} \mathrm{X}_{2}+0.043 \mathrm{X}_{1} \mathrm{X}_{3}+0.016 \mathrm{X}_{1} \mathrm{X}_{4}+0.009 \mathrm{X}_{2} \mathrm{X}_{3}+0.004 \mathrm{X}_{2} \mathrm{X}_{4}-0.06 \mathrm{X}_{3} \mathrm{X}_{4}$

F-value of 4.13 for nattokinase activity implied that the model is significant with high satisfactory value of $\mathrm{R}^{2}$ of $79.4 \%$. RSM can be used to find the relationship among process variables and response in an efficient manner using minimum number of experiments (Nadyaini et al., 2011). It was demonstrated that the combined use of Plackett-Burman design and response surface methodology plenty of optimization work has been conducted to increase nattokinase production, rare of the optimization of soil microorganism fibrinolytic enzyme using statistical experimental methods has been reported.

The $P$ value for lack of fit was 0.192 , not significant. So we could make the conclusion that the model exactly reflects the relationship of every factor. $\underline{\text { P-values }}(\mathrm{p})$ is to determine which of the effects in the model are statistically significant Table (5).

Table 5:- Analysis of Variance for Response

\begin{tabular}{|c|c|c|c|c|c|c|}
\hline Source & DF & Seq SS & Adj SS & Adj MS & $\mathbf{F}$ & $\mathbf{P}$ \\
\hline Regression & 14 & 0.072699 & 0.072699 & 0.005193 & 4.13 & 0.005 \\
\hline Linear & 4 & 0.022667 & 0.030320 & 0.007580 & 6.03 & 0.004 \\
\hline Glucose & 1 & 0.000008 & 0.009216 & 0.009216 & 7.33 & 0.016 \\
\hline Maltose & $\mathbf{1}$ & 0.000864 & 0.000271 & 0.000271 & 0.22 & 0.649 \\
\hline Peptone & $\mathbf{1}$ & 0.001262 & .021735 & 0.021735 & 17.29 & 0.001 \\
\hline Yeast extract & 1 & $\mathbf{0 . 0 2 0 5 3 3}$ & 0.006679 & 0.006679 & 5.31 & 0.036 \\
\hline Square & 4 & 0.002801 & 0.002801 & 0.000700 & 0.56 & 0.697 \\
\hline Glucose*Glucose & 1 & 0.000009 & 0.000020 & 0.000020 & 0.02 & 0.901 \\
\hline Maltose*Maltose & 1 & $\mathbf{0 . 0 0 0 3 3 6}$ & 0.000309 & 0.000309 & 0.25 & 0.627 \\
\hline Peptone*Peptone & $\mathbf{1}$ & 0.001289 & 0.000940 & 0.000940 & 0.75 & 0.401 \\
\hline Yeast*Yeast & 1 & 0.001166 & 0.001166 & 0.001166 & 0.93 & 0.351 \\
\hline Interaction & 6 & 0.047231 & 0.047231 & 0.007872 & 6.26 & 0.002 \\
\hline Glucose*Maltose & 1 & 0.000002 & 0.000002 & 0.000002 & 0.00 & 0.967 \\
\hline Glucose*Peptone & 1 & 0.019321 & 0.019321 & 0.019321 & 15.37 & 0.001 \\
\hline Glucose*Yeast & 1 & 0.005112 & 0.005112 & 0.005112 & 4.07 & 0.062 \\
\hline Maltose*Peptone & 1 & 0.000132 & 0.000132 & 0.000132 & 0.11 & 0.750 \\
\hline Maltose*Yeast & $\mathbf{1}$ & 0.003481 & 0.003481 & 0.003481 & 2.77 & 0.117 \\
\hline Peptone*Yeast & 1 & 0.019182 & 0.019182 & 0.019182 & 15.26 & 0.001 \\
\hline Residual Error & 15 & 0.018859 & 0.018859 & 0.001257 & & \\
\hline Lack- of- fit & 10 & 0.015427 & 0.015427 & 0.001543 & 2.25 & 0.192 \\
\hline Pure Error & 5 & 0.003431 & 0.003431 & 0.000686 & & \\
\hline Total & 29 & 0.091558 & & & & \\
\hline
\end{tabular}




\section{Response Optimization:-}

According to the regression equation, the relationship between every two variables could be directly reflected by drawing a three-dimensional (3D) plot of response curve while keeping the third one at middle level. To obtain the maximum optimum activity, the factors level were set at the values given using Minitab's Multiple Response Optimizer under global solution of desirability equal to one. That is, glucose at $1.45 \%$, maltose at $5.5 \%$, yeast extract at $2.75 \%$ and with no level of peptone incorporated to the medium. The global solution of these different variable levels would result in $0.80 \mathrm{FU} / \mathrm{ml} \mathrm{FU}$ as predicated response of the enzyme activity. In addition to establishing optimal fermentation medium compositions, the present methodology also makes it possible to predict the yield if the composition of the medium is altered in some way, by using the quadratic equation above. According to the previous report using the medium components peptone, calcium chloride and yeast extract resulted in maximum nattokinase activity of $1300 \mathrm{U} / \mathrm{ml}$ (Liu et al., 2005). Our results disagree with the findings of ZHANG et al 2013 who found that peptone and magnesium sulfate promoted fibrinolytic enzyme yield. This result not agree with Deepak et al., (2008) where the statistical analysis of their results showed that only peptone had significant effect on nattokinase production. Also not agree with (Lui et al., 2005) where their results indicated that soya peptone, yeast extract and $\mathrm{CaCl}_{2}$ have significant effect on nattokinase production. The three-dimensional graphs and contour graphs are the common graphical representation of the regression equation which shows the optimal values of each dependent variable (Chen et al., 2008). According to the regression equation, the relationship between every two variables could be directly reflected by drawing a three-dimensional (3D) plot of response curve and contour graphs, while keeping the third one at middle level. Fig. (3), (4), (5) and (6). Findings of ZHANG et al., 2013 revealed that the predicted maximal fibrinolytic enzyme using statistical experimental method yield was 19.78 $\mathrm{FU} / \mathrm{mL}$ with $11.4 \mathrm{~g} / \mathrm{L}$ peptone, $0.5 \mathrm{~g} / \mathrm{L}$ magnesium sulfate and $1 \mathrm{~g} / \mathrm{L}$ sodium chloride, and maximal production of $21.33 \mathrm{FU} / \mathrm{mL}$ in actual experiments, equal to $107.84 \%$ of the theoretical value, and the yield had been increased by $79.55 \%$ as compared to the yield of un-optimized culture

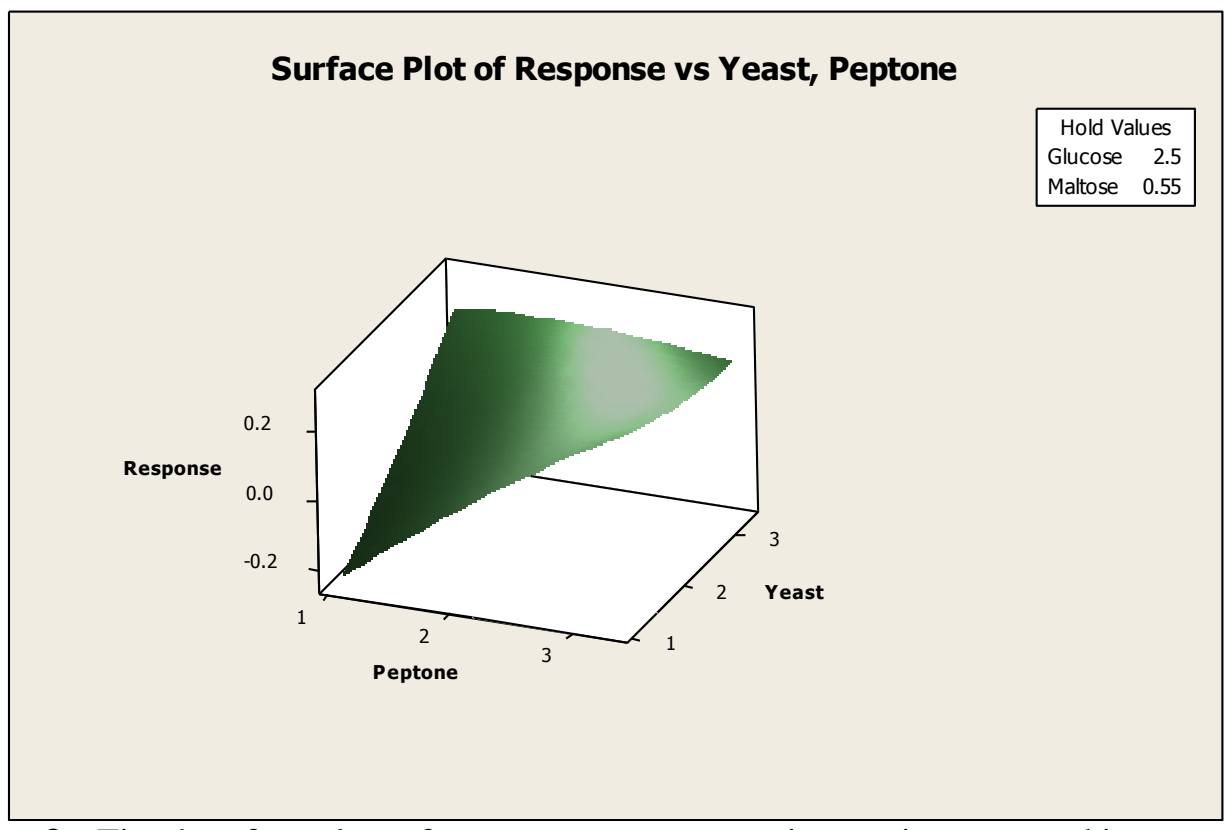

Figure 3:- Fitted surface plots of yeast extract- peptone interaction on nattokinase activity 


\section{Surface Plot of Response vs Yeast, Maltose}

Hold Values

Glucose $\quad 2.5$

Peptone 1.25

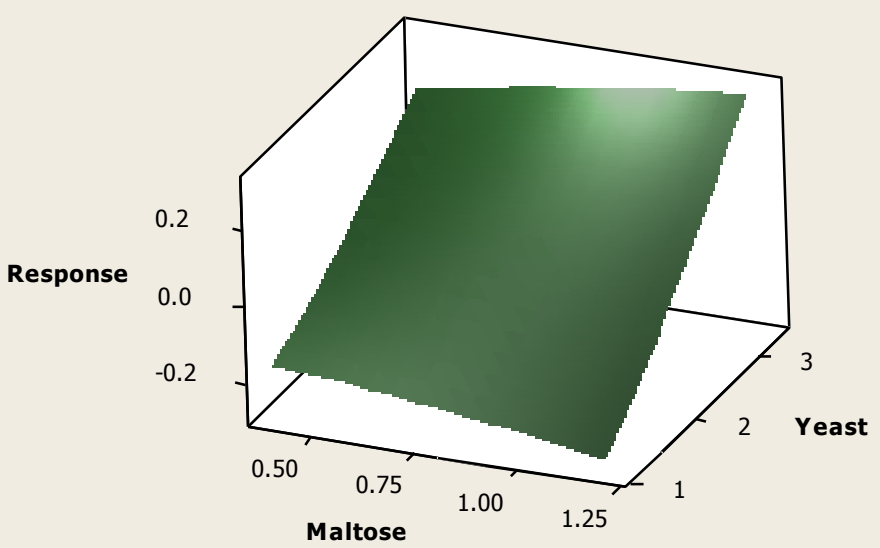

Figure 4:- Fitted surface plots of yeast extract- maltose interaction on nattokinase activity

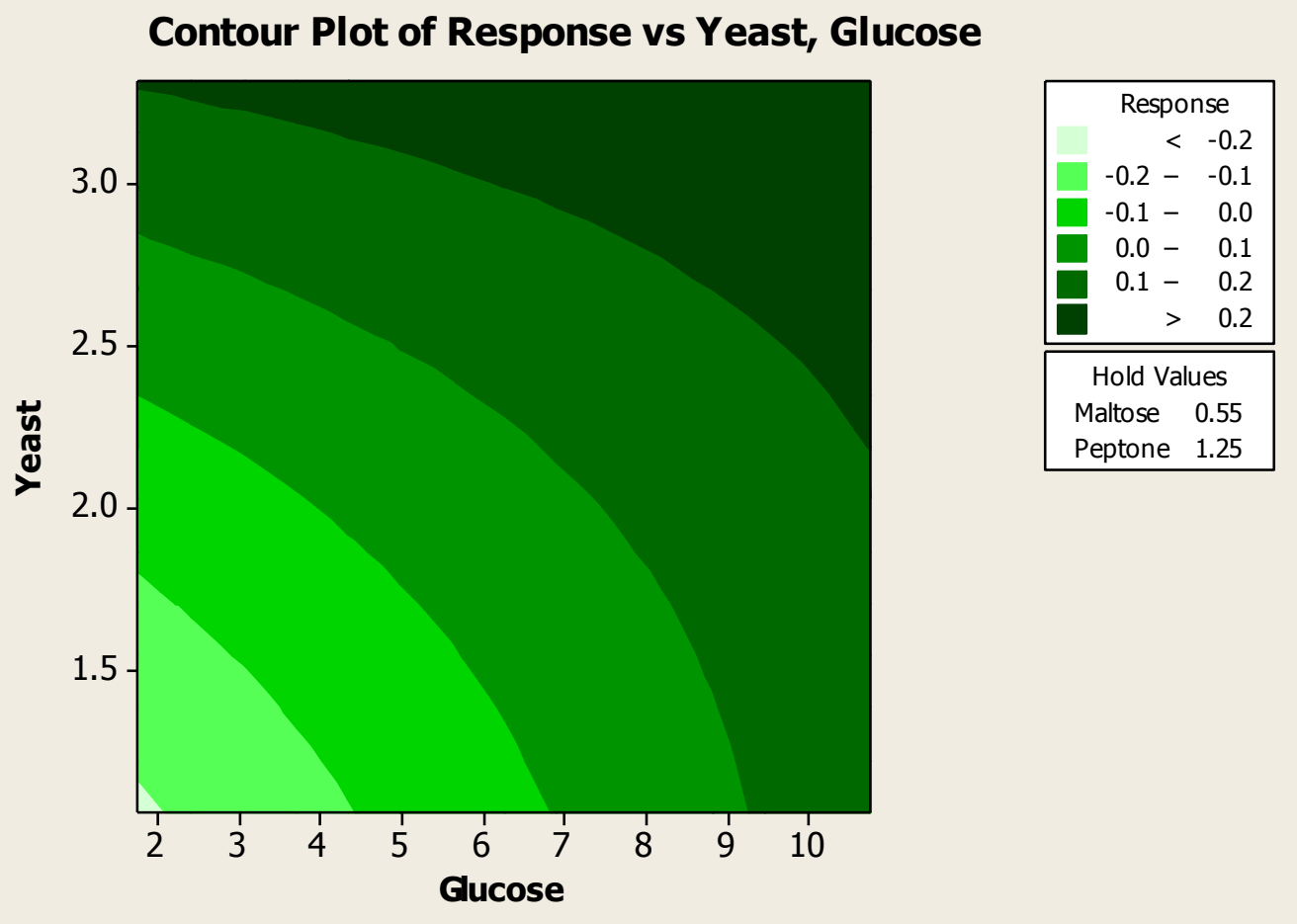

Figure 5:- Fitted surface plots of yeast extract- glucose interaction on nattokinase activity 


\section{Contour Plot of Response vs Yeast, Maltose}
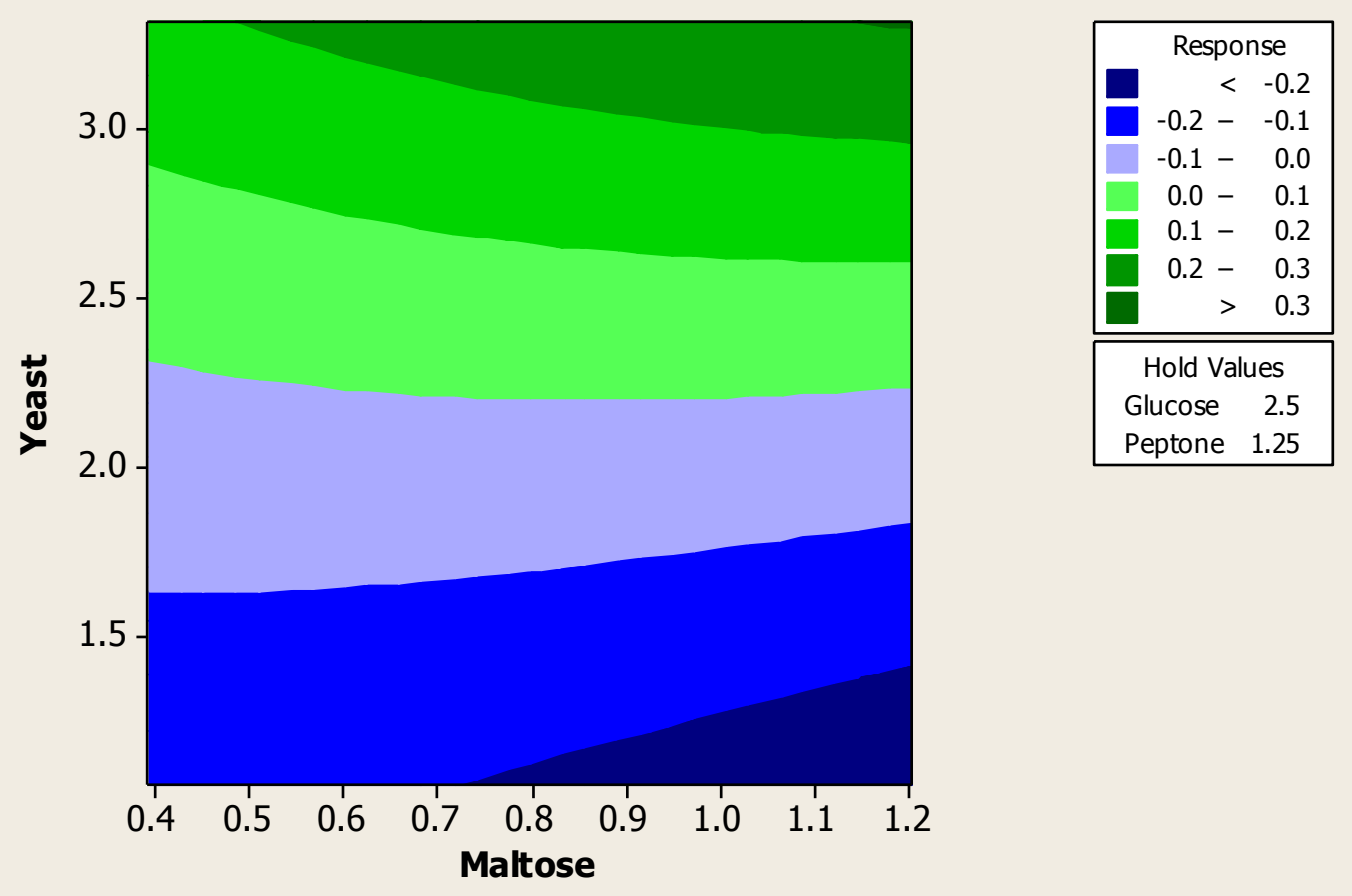

Figure 6:- Fitted surface plots of yeast extract- maltose interaction on nattokinase activity

\section{Conclusion:-}

Thirty soil samples that collected from different location in Sudan. Sixteen out of thirty samples (53\%) were consider as Bacillus subtilis according to morphological, ,microscopic and biochemical characteristics . Primary screening indicated that only ten samples out of sixteen (63) showed positive nattokinase production by casein hydrolysis and blood hemolysis assays. The maximum optimum activity was obtained under global solution of desirability equal to one. That is, glucose at $1.45 \%$, maltose at $5.5 \%$, yeast extract at $2.75 \%$ and with no level of peptone incorporated to the medium. The predicated response of the enzyme activity is $0.83 \mathrm{FU}$.

\section{Acknowledgment:-}

Authors gratefully acknowledge Bacteriology Dept. Central Lab. Ministry of Higher Education and Scientific Research for their help and support during lab. work.

\section{References:-}

1. Borah, D. Yadav, R. Sangra, A. Shahin L. and Chaubey A. 2012. Production, purification and characterization of nattokinase from Bacillus subtilis, isolated from tea garden soil samples of dibrugarh, assam. Asian journal of pharmaceutical and clinical research. 5:0974-2441:124-125.

2. Chen, X. Wei, D. Liu, D. 2008. Response surface optimization of biocatalytic biodiesel production with acid oil. Biochem. Eng. J., 40: 423429.

3. Collins, C. and Lynee, P. 1995 Microbiological Methods $7^{\text {th }}$ edition. Butterworth-Heminemann Ltd. Pp 493.

4. Deepak, V. Kalishwarala,1 K. Ramkumarpandian, S. Venkatesh Babu, S. Senthilkuma,r S. R and Sangiliyandi, G. 2008. Optimization of media composition for nattokinase production by Bacillus Subtilis using response surface methodology. Bioresource Technology.99(17):8170-8174.

5. Dubey, R. Kumar, J. Agrawala, D. Char, T. and Pusb, P. 2011. Isolation, production, purification, assay and characterization of fibrinolytic enzymes (Nattokinase, Streptokinase and Urokinase) from bacterial sources. African Journal of Biotechnology. 10(8):1684-5315:1408-1420.

6. Ibrahim, H. M. Elkhidir, E. E. 2011. Responnse Surface Method as an Efficient Tool for Medium Optimisation. Trends in Applied Sciences Research 6(2):121-129,2011. 
7. Haritha, M. Meena, V. Angalapati. 2011. Nattokinase: A review of fibrinolytic enzyme. Chemical, environmental and pharmaceutical research. 2(1):61-66.

8. Ibrahim, H..M. Obeid, A. and Alawad, A. 2015. Isolation and Characterization of Bacillus Subtillus with potential production of nattokinase. International Journal of Advanced Resesrch.3(3): 94-101.

9. Ibrahim, H.M. Kowther Isameldein Bashir, Elrashied Elimam Elkhidir, Mawa Ibrahim Alnour and Omayma Elyas1 2015 Statistical Optimization of Culture Conditions for Nattokinase Production by Batch Fermentation. Int.J.Curr.Microbiol.App.Sci 4(11): 143-153

10. Isam Eldeen K, Hanan Moawia Ibrahim, Elrashied Elimam Elkhisi,r and Hassan Beshir Elamin 2015. Optimization of Culture Conditions to Enhance Nattokinase Production Using RSM. American Journal of Microbiological Research. 3(5), 165-170

11. Katazong Betraum, G. 2007. Basic and Clinical Pharmacology $10^{\text {th }}$ Ed.

12. Kwon, E. Y. Kim, K. M. Kim, M. K. Lee, I. Y. Kim, B. S. 2011. Production of nattokinase by high cell density fed-batch culture of Bacillus Subtilis .Bioprocess and Biosystems Engineering 34 (7): 789-793.

13. Kim, S. H. and Choi, N. S. 2000. Purification and characterization of subtilisin DJ-4 secreted by Bacillus sp. strain DJ-4 screened from Doen-Jang, Biosci. Biotechnol.Biochem. 64 1722-1725.

14. Kwang-Min, L. David, F. G. 2005. Formulation and process modeling of biopolymer (polyhydroxyalkanoates: PHAs) production from industrial wastes by novel crossed experimental design. Process Biochem. 40, 229-246.

15. Liu, J. Xing, J. Chang, T. Ma, Z. and Liu, H. 2005. Optimization of nutritional condition for nattokinase production by Bacillus natto NLSSE using statistical experimental methods. Process Biochemistry. 40(8) :27572762.

16. Martin Milner, N. D. and Kouhei Makise M. D. 2002. Natto and its active ingredient Nattokinase, atternative and complementary therapies.

17. Myers, R. H, D. C. Montgomery, and C. M. Anderson-Cook, 2009. Response Surface Methodology: Process and Product Optimization Using Designed Experiments, Wiley, New York, NY, USA, 3rd edition.

18. Nadyaini, W. N. Omar, W. Aishah, N. Amin, S. 2011. Optimization of heterogeneous biodiesel production from waste cooking palm oil via response surface methodology. Biomass Bioenergy, 35: 13291338.

19. Peng, Y. Huang, Q. Zhang, R.H. 2003 Purification and characterization of a fibrinolytic enzyme produced by Bacillus amyloliquefaciens DC-4 screened from douchi, atraditional Chinese soybean food. Comp Biochem Phys. 134(1):45-52

20. Prasad Sweta, Rajpal, S. Kashyap, Jayant, Y. Deopujari, Heman,t J. Purohit, Girdhar, M. Taori, and Hatim, F. Daginawala. 2006. Development of an in vitro model to study clot lysis activity of thrombolytic drugs. Thrombosis Journal, vol. 4(14)

21. Rang, H. P. Dale, M. M. Ritter, J. M. and Moore, P. K. 2003. Pharmacology Edition ${ }^{5}$.

22. Sumi, H. Hamada, H. Nakanishi, K. and Hiratani, H. 1990. Enhancement of the fibrinolytic activity in plasma by oral administration of Nattokiase .Acta. Haematol 84 (3):139-143.

23. Tillett, W. and Garner, R. 1933. The fibrinolytic activity of hemolytic Streptococci. J. Exp. Med. 58:485.

24. Wu, S. Y. 2005. Optimization of nutritional conditions for Nattokinase production by an isolated Bacillus subtilis from natto health food. Thesis for Master Science, Tatung University, Cited in: ZHANG Xu, Luo-jia YUN, Liang-bin PENG, Yi LU, Kun-peng MA and Fei TANG ( 2013 ) "Optimization of Douchi Fibrinolytic Enzyme Production by Statistical Experimental Methods" J Huazhong Univ Sci Technol [Med Sci] 33(1):153-158,2013

25. Uversky, V. and Fink, A. 2004. Comformational constraints for amyloid fibrillation: the importance of being unfolded .Biochem. Biophys. Acta .1698:131-153.

26. Willim, S. and Cross, T. 1971. Method in Microbiology. Edited by Booth. Academic Press, London and NewYork. Pp795.

27. You, K. M. and Park, Y, K. 2004. A new method for the selective isolation of Actinomycetes from soil . Biotechnol. Techn.10:541-546.

28. ZHANG, Xu, Luo-jia Y. U. N. Liang-bin PENG, Yi, L.U. Kun-peng M. A. and Fei, TANG. 2013. Optimization of Douchi Fibrinolytic Enzyme Production by Statistical Experimental Methods" J Huazhong Univ Sci Technol [Med Sci] 33(1):153-158,2013 